Ciência Florestal, Santa Maria, v. 25, n. 1, p. 257-271, jan.-mar., 2015

ISSN 0103-9954

\title{
PRESERVAÇÃO DE MADEIRAS NO BRASIL: HISTÓRICO, CENÁRIO ATUAL E TENDÊNCIAS
}

\author{
WOOD PRESERVATION IN BRASIL: HISTORICAL, CURRENT SCENARIO AND TRENDS
}

\author{
Jackson Marcelo Vidal $^{1}$ Wescley Viana Evangelista ${ }^{2}$ Jose de Castro Silva ${ }^{3}$ Ivaldo Pontes Jankowsky ${ }^{4}$
}

\section{RESUMO}

O objetivo deste trabalho foi apresentar uma revisão de literatura sobre o setor de preservação de madeiras no Brasil, desde seu início até o ano de 2011. O Brasil é rico em recursos naturais e a madeira sempre ocorreu de forma abundante. Com o crescimento industrial, houve a necessidade de utilizar madeiras de baixa durabilidade natural, mas dependentes de um tratamento preservativo. O tratamento de madeiras iniciou-se no final do século XIX, para atendimento da demanda de dormentes para as ferrovias. Somente na década de 1960, o setor de preservação de madeiras ganhou impulso com aumento significativo das pesquisas científicas, normalização técnica e unidades industriais de preservação de madeira. A partir daí, poucos avanços foram observados. No ano de 2011, as usinas de preservação utilizam basicamente madeiras dos gêneros calyptus e Pinus, realizando, principalmente, o tratamento preservativo em usinas sob pressão. Em pequena escala, utiliza-se o método de substituição de seiva. Os principais preservativos utilizados são o arseniato de cobre cromatado (CCA) e o borato de cobre cromatado (CCB); o creosoto também é utilizado, em reduzida escala. A produção de madeira tratada concentra-se, essencialmente, na produção de moirões de cerca, postes e dormentes. Como tendência, o setor deverá alcançar novos mercados, como o de construção civil, cruzetas e embalagens, bem como intensificar o consumo dos produtos tradicionais. A despeito de inúmeras pesquisas sobre vários produtos, o CCA deverá se manter no mercado por vários anos, pela inexistência de produtos alternativos que apresentem a mesma eficácia, bem como à inexistência de provas que o produto apresente efeitos nocivos à saúde humana e ao meio ambiente.

Palavras-chave: madeira tratada; $\mathrm{CCB}$; CCA.

\begin{abstract}
The objective of this paper was to show a comprehensive literature review about wood preservation in Brazil, since the earliest years until 2011. Brazil is rich in natural resources and wood has always occurred in abundance. With the industrial growing, there was the necessity of using wood with low natural durability but with chemical preservative treatment. Wood chemical treatment began in late XIX century, mainly to attend the big demand of sleepers to railroads. Only during the 60's, wood preservation gained market with the increase of scientific researches, elaboration of technical standards and building industrial plants for wood preservation. From this point on, few advances have been reached. In 2011, Eucalyptus and Pinus, were the main species used in wood preservation plants that adopts the vacuum-pressure process. In small production scale, diffusion process is adopted. Copper chromium arsenate (CCA) and Copper chromium borate $(\mathrm{CCB})$ are the most preservatives utilised with some creosote utilisation. The treated

1 Químico, Msc., Mestre em Ciências Florestais, Escola Superior de Agricultura "Luiz de Queiroz", Universidade de São Paulo, Caixa Postal 09, CEP 13418-900, Piracicaba (SP), Brasil. jmvidal@usp.br

2 Engenheiro Florestal, Dr., Doutor em Ciência Florestal, Universidade Federal de Viçosa, Av. P.H. Rolfs, s/n, CEP 36570-000, Viçosa (MG), Brasil.wescleyviana@yahoo.com.br

3 Engenheiro Florestal, Dr., Professor Adjunto do Departamento de Engenharia Florestal, Universidade Federal de Viçosa, Av. P.H. Rolfs, s/n, CEP 36570-000, Viçosa (MG), Brasil. jcastro@ufv.br

4 Engenheiro Florestal, Dr., Professor Associado do Departamento de Ciências Florestais, Escola Superior de Agricultura "Luiz de Queiroz", Universidade de São Paulo, Caixa Postal 09, CEP 13418-900, Piracicaba (SP), Brasil.jankowsky@usp.br
\end{abstract}

Recebido para publicação em 3/08/2011 e aceito em 3/07/2013

Ci. Fl., v. 25, n. 1, jan.-mar., 2015 
wood production is concentrated in fence posts, poles and sleepers. As a trend, the wood preservation must reach new markets, such as building constructions, wood packages and crossarms, and also to intensify the traditional uses. Although there are a lot of researches about chemicals for wood preservation, CCA must keep by the years, once alternative products do not present the same efficacy or clear effects about human health and environment.

Keywords: treated wood; CCB; CCA.

\section{INTRODUÇÃO}

O setor florestal brasileiro apresenta grande importância para a economia do País, contribuindo com cerca de $3,5 \%$ do produto interno bruto (PIB), no ano de 2010. A despeito de ter uma área de cobertura florestal nativa de $60,7 \%$ do território brasileiro, o aproveitamento dos recursos naturais madeireiros é insignificante, em função do potencial que representa. Segundo a Associação Brasileira de Florestas Plantadas, a ABRAF (2011), o setor é caracterizado principalmente pelos plantios florestais de rápido crescimento, com espécies dos gêneros Eucalyptus e Pinus, situados na sua maioria, nos Estados das regiões Sudeste e Sul, respectivamente.

A madeira é um material renovável cujas propriedades físico-mecânicas e anatômicas a tornam um material versátil. Em relação a outros materiais, como o concreto, plástico, aço e alumínio, a madeira apresenta uma série de vantagens, como beleza, alta resistência mecânica em relação à massa, baixo consumo energético para o seu processamento, bom isolamento térmico, fácil trabalhabilidade. Apresenta, também, desvantagens, como material combustível e, para algumas espécies, baixa durabilidade natural, rachaduras e empenamentos.

O desconhecimento dos atributos e características da madeira inviabiliza a sua correta utilização. Para tanto, faz-se necessária a avaliação de determinadas propriedades, adequando-as às madeiras em condições de uso. Do ponto de vista da preservação, alguns parâmetros devem ser observados: escolha da espécie da madeira, com base nas propriedades intrínsecas de durabilidade natural e tratabilidade; definição do risco biológico a que a madeira será submetida; adoção do método de tratamento e produto preservativo em função do risco biológico, visando ao aumento da durabilidade da madeira. Em situações de maior risco e exposição aos agentes que degradamamadeira, comomoirões, postes, dormentes e alguns componentes de construção, é necessário o uso de madeiras de alta durabilidade natural, que lhe garantam maior resistência ao ataque de agentes xilófagos, principalmente. Madeiras reconhecidamente de alta durabilidade natural não estão mais disponíveis no mercado e, gradualmente, estão sendo substituídas por outras de rápido crescimento, exigindo, em contrapartida, tratamento preservativo. Tal tratamento se torna imprescindível para aumentar a vida útil dessas madeiras, bem como contribuir com a preservação das florestas nativas.

Segundo Revista da Madeira (2007), a preservação de madeiras é qualquer procedimento ou conjunto de medidas que possa conferir à madeira em uso maior resistência aos agentes de deterioração, proporcionando-lhe maior durabilidade. Tais agentes podem ser de natureza física, química e biológica (agentes xilófagos), que afetam suas propriedades. $O$ tratamento preservativo é imprescindível para madeiras de baixa durabilidade natural ou para porções permeáveis e passíveis de tratamento, como o alburno. A eficácia do tratamento é avaliada por meio da retenção e penetração de produtos, garantidas pelos níveis mínimos recomendados pelas normas técnicas. No mercado, existem diversos produtos preservativos, de natureza hidrossolúvel ou oleossolúvel, para tratamento preventivo ou curativo; diversos métodos são utilizados, com pressão atmosférica ou pressões artificiais. A combinação de produtos e processos confere à madeira padrões de qualidade diversos, adequando-a aos diferentes usos.

No Brasil, emprega-se um baixo volume de madeira tratada, quando comparado a outros países, como os Estados Unidos e Inglaterra. A quantidade de madeira utilizada pelo setor é insignificante quando comparada a outros setores industriais do país, como celulose e papel, carvão vegetal e painéis reconstituídos. O setor, 
entretanto, apresenta grandes potencialidades de expansão e crescimentos, rumo a novos mercados emergentes, como da construção civil, embalagens e linhas de transmissão (cruzetas e postes). O objetivo deste trabalho foi apresentar uma revisão de literatura sobre o setor de preservação de madeiras no Brasil, desde o seu início até o ano de 2011, mostrando sua situação atual e tendências.

\section{HISTÓRICO DA PRESERVAÇÃO MADEIRAS NO BRASIL}

$\mathrm{O}$ primeiro registro que se tem conhecimento sobre preservação de madeiras no Brasil é datado em 1587, quando o senhor de engenho, Gabriel Soares de Souza, escreveu sobre a infestação de cupins subterrâneos em habitações, ataque de brocas de madeiras e perfuradores marinhos, durabilidade de madeiras em diferentes locais e sobre a maior durabilidade do cerne em relação ao alburno. Somente no século XIX houve novos registros, a partir da necessidade do uso de dormentes para as ferrovias em construção (CAVALCANTE, 1986).

Como nos outros países, o uso de madeira tratada, no Brasil, surgiu em decorrência do desenvolvimento industrial, que trouxe a necessidade de transportes mais rápidos, novos meios de comunicações e melhores fontes de energia. Surgiu, assim, uma demanda de madeira com alta resistência ao ataque de xilófagos para as ferrovias, telégrafos, telefonia e eletrificação. O uso industrial de madeira preservada teve início entre 1880 e 1884, com o emprego de dormentes tratados com creosoto para as ferrovias. A necessidade de madeira tratada ocorreu pela escassez de madeiras nativas de alta durabilidade natural, bem como pela resistência às intempéries. Na construção da estrada de ferro Madeira-Mamoré, em 1907, em plena Floresta Amazônica, embora houvesse disponibilidade de grande número de madeiras de alta durabilidade natural, optou-se pela importação de 80.000 dormentes de eucalipto, provenientes da Austrália (CAVALCANTE, 1986).

A primeira usina de tratamento de madeiras sob pressão foi importada da Inglaterra pela antiga Estrada de Ferro Central do Brasil e instalada no município de Juiz de Fora, Minas Gerais, entre 1902 e 1904, para tratamento de dormentes com creosoto. A partir dessa década, os documentos disponíveis não indicam nenhum acontecimento relevante até a década de 1930. O primeiro estudo sobre preservação de madeiras foi desenvolvido por Brotero (1933) e objetivava avaliar a penetração de um preservativo hidrossolúvel em estacas, aplicado por imersão, bem como o efeito do tratamento nas propriedades mecânicas da madeira e o aumento da vida útil conferida a esse material. Nessa época, houve também registro de dois outros estudos: um foi desenvolvido por Edmundo Navarro de Andrade, envolvendo o tratamento de peças roliças com creosoto, por banho quente-frio; e outro, desenvolvido por Djalma Guilherme de Almeida, em 1939, visando avaliar a resistência de várias madeiras ao ataque de cupins, assim como testar a eficiência do tratamento da madeira com pentaclorofenol. A primeira empresa privada de preservação de madeiras, a Preservação de Madeiras Ltda., foi fundada nessa época, especificamente em 1936 (CAVALCANTE, 1986).

$\mathrm{Na}$ década de 1940, houve aumento do número de pesquisas relacionadas à eficiência de preservativos e ensaios de campo, sendo realizada também a instalação da primeira usina de tratamento, sob pressão, pela Preservação de Madeiras Ltda., utilizando-se de um produto à base de fluoreto-dicromato-dinitrofenol. $\mathrm{Na}$ década de 1950, houve a continuação dos estudos científicos e a instalação da segunda usina de tratamento de madeiras, pela Companhia Vale do Rio Doce, em Governador Valadares, Minas Gerais. Houve, também, nesse período, a instalação de mais três usinas de capital privado e o início da fabricação de preservativos no País (CAVALCANTE, 1986).

$\mathrm{Na}$ década de 1960, foi publicada a primeira dissertação de mestrado em preservação de madeiras. Nesse período, houve a instalação de novas usinas de tratamento da madeira e a promulgação da Lei Federal nº. 4797, de 20/10/1965, dos Decretos Lei $n^{\circ}$. 58.016, de 18/03/1966, e de $\mathrm{n}^{\mathrm{o}}$. 61.248, de 30/09/1967, que regulamentavam o emprego de madeira tratada em serviços públicos. Em 25 de agosto de 1969 foi criada a primeira entidade de classe, a Associação Brasileira dos Preservadores de Madeira (ABPM), com sede no Instituto de Pesquisas Tecnológicas (IPT), na cidade de São Paulo.

$\mathrm{Na}$ década de 1970, houve aumento expressivo no número de publicações, oriundas 
de universidades, centros de pesquisa e empresas, com o objetivo de divulgação de técnicas de preservação da madeira, estudos de durabilidade natural, eficiência de produtos, bem como cuidados operacionais no tratamento e uso da madeira tratada. Os consumidores de produtos de madeira tratada apresentaram seus questionamentos sobre a vida útil dos postes. Na época, a ausência de informações e de normas técnicas levou ao descrédito o uso de postes de madeira, colocando-o em desvantagem no mercado em relação aos outros materiais, como poste de concreto. Nessa década, houve maior atuação da ABPM e do IPT, no sentido de corrigir o mau conceito do poste de madeira tratada no Brasil. Em 1973, a Associação Brasileira de Normas Técnicas (ABNT) publicou duas normas importantes para o setor: a norma EB-596 "Postes de eucalipto preservados sob pressão" e a MB-790 "Penetração e retenção de preservativo em postes de madeira". Tais normas foram muito importantes para conferir maior respaldo técnico desses produtos. Um novo crescimento no consumo de postes de madeira tratada começou a surgir a partir da década de 1980 (CAVALCANTE, 1986).

Segundo Madtrat (2008), entre 1970 e 1980 , o número de indústrias de preservação da madeira aumentou em $318,75 \%$, o que pode ser explicado pelo grande desenvolvimento brasileiro nos setores de transportes e energia. Em 1982, havia no Brasil 13 usinas de tratamento de madeiras; entre 1995 e 1996, já haviam sido registradas 68 usinas, com capacidade de produção anual estimada em 865 mil metros cúbicos. Destas indústrias, 14 estavam inativas, 14 pertenciam a empresas estatais dos setores ferroviário e elétrico e 40 usinas privadas. No ano de 2000, segundo estimativas da ABPM, existiam em operação 80 usinas, com uma produção estimada em 560 mil metros cúbicos de madeira preservada, sendo a maior parte dessa produção destinada ao segmento rural, seguido pelo elétrico, ferroviário e de madeira serrada. Segundo o autor, ao contrário de outros países, a indústria brasileira de preservação de madeiras praticamente não diversificou sua produção.

\section{CÉNARIO ATUAL DO SETOR DE PRESERVAÇÃO DE MADEIRAS}

\section{Principais matérias-primas utilizadas}

Segundo o serviço Florestal Brasileiro (2010), o Brasil possuía, no ano de 2009, uma área florestal de 516,6 milhões de hectares, sendo 509,8 milhões formados por florestas nativas e 6,8 milhões formados por plantios florestais. Segundo ABRAF (2011), no ano de 2010, existiam no Brasil, 6.973.083 ha de plantios florestais, sendo 4.754.334 ha de Eucalyptus, 1.756 .359 ha de Pinus e 462.390 ha formados por plantios de outras espécies. Segundo Netto (2010), as restrições ao uso de madeira tropical de florestas nativas não certificadas têm contribuído para o uso consciente e racional de madeiras dos plantios florestais, especialmente de espécies dos gêneros Pinus e Eucalyptus, por apresentarem elevada taxa de crescimento, produção e preços competitivos, homogeneidade de material e regularidade de abastecimento. Com isso, a indústria de preservação de madeiras no Brasil tem utilizado principalmente as madeiras dessas espécies, diminuindo, também, a pressão de corte sobre as florestas nativas. Ademais, as árvores em crescimento sequestram o gás carbônico da atmosfera, reduzindo os impactos negativos do efeito estufa.

\section{Usos da madeira tratada}

No ano de 2011, os principais produtos de madeira tratada foram moirões, estacas, postes, dormentes e peças roliças e serradas para a construção civil. Todos esses produtos apresentam inúmeras vantagens e potencialidades de maior consumo, principalmente nos setores rural e de construção civil (NETTO 2010).

O moirão é o produto de madeira tratada mais utilizado no Brasil, principalmente no meio rural. Segundo Geraldo (2008), não existem estatísticas oficiais do setor que apontam o número de moirões produzidos, estimando-se uma média anual de 40 milhões de unidades. Esse mercado evoluiu consideravelmente, pois promoveu uma substituição gradativa de madeiras nativas por madeira roliça de plantios de rápido crescimento, com características similares e maior disponibilidade.

$\mathrm{O}$ uso de postes de madeira tratada continua promissor, principalmente em programas governamentais que promovem a eletrificação da área rural do País. Segundo Geraldo (2001) e Francischinelli (2006), países de grande tradição 
florestal, como a Alemanha, Suécia, Estados Unidos e Finlândia, e mesmo países carentes de recursos florestais, como a Inglaterra, preferem os postes de madeira tratada, por causa da economia que proporcionam na construção de redes rurais de energia. Os postes de madeira tratada apresentam muitas vantagens em relação aos postes de concreto e metálico: produto renovável, que demanda baixa energia para a sua produção; baixa condutividade elétrica, o que reduz os riscos de acidentes e desligamentos por fugas ou descargas elétricas; maior suporte de tensão de impulso atmosférico, em relação aos postes metálicos; é mais leve que o poste de concreto, diminuindo os custos de transporte; maior resistência mecânica ao choque; maior facilidade de instalação; menor necessidade de acessórios, como por exemplo, ferragens, travessas, proporcionando economia de escala. O poste de madeira tratada é um produto competitivo, de vida útil prolongada e apresenta custo anual inferior aos postes produzidos com outros materiais, como o concreto. A desvantagem do poste de madeira tratada se resume na combustibilidade e biodegradabilidade do material, exigindo-se inspeções e manutenções periódicas A madeira de eucalipto é a mais utilizada na fabricação de postes, embora a madeira de Pinus também possa ser utilizada.

Com relação aos dormentes, a madeira, o concreto, o aço e o plástico têm sido utilizados como matérias-primas, no Brasil. Alves e Sinay (2005), ao referirem outros autores, destacaram as vantagens e desvantagens de cada um desses materiais, conforme pode ser visto na Tabela 1. As autoras destacaram o uso promissor da madeira de eucalipto na fabricação de dormentes, em função do conhecimento acumulado das propriedades de várias espécies do gênero, sendo uma importante espécie para o atendimento desse setor.

O dormente de madeira tratada apresenta, ainda, as seguintes vantagens: baixo consumo de energia na sua produção; leve e fácil manuseio; fácil serragem, furação e entalho; são pouco afetados durante seu transporte durante sua instalação na via férrea; não sofrem influência de resíduos industriais poluidores da atmosfera; além de uso da matéria-prima renovável (ALVES e SINAY, 2005).

O uso de madeira tratada na construção civil, seja rural ou urbana, tem se mostrado bastante promissor. Segundo Calil Júnior e Dias (2005), a relação resistência/densidade da madeira é cerca de três vezes maior que para o aço e 10 vezes maior que para o concreto. Em termos de energia necessária para a sua produção e da relação energia/resistência, a madeira apresenta grande vantagem em relação ao aço e ao concreto, mostrando ser o mais ecológico desses materiais. Segundo Steiner (2000), a madeira roliça, tratada em autoclave, pode ser empregada em conjunto com concreto, alvenaria, estruturas metálicas e vidros ou de forma exclusiva. Além disso, deve-se enfatizar que a madeira roliça amplia consideravelmente o espectro de recursos estéticos, prestando-se, tanto a projetos simples e rústicos, quanto a projetos de grande sofisticação e elegância. Segundo Netto (2010), a preservação de madeiras, na construção civil, possibilitou o uso de madeiras de baixa resistência natural em áreas

TABELA 1: Avaliação comparativa entre diversos materiais utilizados para fabricação de dormentes.

TABLE 1: Comparative evaluation between several used materials in the production of sleepers.

\begin{tabular}{|c|c|c|c|c|}
\hline \multirow{3}{*}{ Características } & \multicolumn{4}{|c|}{ Material } \\
\hline & Madeira & Aço & Concreto & Plástico \\
\hline & $\begin{array}{l}\text { Elevado módulo de elasticidade e } \\
\text { grande flexibilidade }\end{array}$ & $\begin{array}{c}\text { Média } \\
\text { estabilidade }\end{array}$ & $\begin{array}{l}\text { Alta durabilidade e } \\
\text { baixa estabilidade }\end{array}$ & $\begin{array}{c}\text { Alta } \\
\text { leveza }\end{array}$ \\
\hline Custo de aquisição & Baixo & Alto & Alto & Alto \\
\hline Durabilidade & Média (15 anos) & Alta (50 anos) & Alta & Alta \\
\hline Reutilização & Sim & Sim & Não & Sim \\
\hline $\begin{array}{l}\text { Necessidade de tratamento } \\
\text { preservativo preventivo }\end{array}$ & Sim & Não & Não & Não \\
\hline $\begin{array}{l}\text { Resistência a } \\
\text { descarrilamentos }\end{array}$ & Alta & Alta & Baixa & Baixa \\
\hline
\end{tabular}

Fonte: Alves e Sinay (2005). 
de grande agressividade, como aquelas expostas ao intemperismo, umidade permanente, contato com o solo, bem como aquelas utilizadas em projetos estruturais. Com isso, recomenda-se o uso de madeira tratada em estruturas para telhados, lambris e forros, peças roliças perfiladas para sistemas construtivos log homes, pisos, vigas roliças estruturais, vigas perfiladas e peças serradas para pisos.

Outras utilizações da madeira tratada são também potenciais. Muitas empresas brasileiras do setor têm investido em produtos alternativos, como pérgolas, móveis rústicos, deques, e playgrounds ou destinado ao setor de paisagismo.

Segundo Netto (2010), em 2010 a indústria de preservação de madeira empregou aproximadamente, 1,3 milhões de metros cúbicos de madeiras, sendo $60 \%$ destinados ao setor rural (moirões, estacas e instalações rurais), 13\% para o setor elétrico (postes e cruzetas), $11 \%$ para o setor ferroviário (dormentes), 15\% para a construção civil (peças roliças e serradas, telhas, estruturas) e $1 \%$ para outros usos, como pisos automotivos e exportações. Existiam, nesse período, 272 usinas de preservação, cadastradas junto ao Instituto Brasileiro do Meio Ambiente e dos Recursos Naturais Renováveis (IBAMA), localizadas, em sua maioria, nos Estados de Minas Gerais, São Paulo, Espírito Santo e Santa Catarina, por causa da maior oferta de madeiras, especialmente de Eucalyptus, além da maior proximidade do mercado consumidor.

O consumo de madeira, na indústria de preservação, é ainda muito baixo quando comparado a outros setores. Segundo ABRAF (2011), no ano de 2010, o consumo brasileiro de madeira, em tora, proveniente de plantios florestais, foi de aproximadamente 170 milhões de metros cúbicos, distribuídos em vários setores, conforme pode ser visto na Tabela 2. Em decorrência da insignificante participação no consumo de madeira tratada no Brasil, a atividade não é, nem mesmo, mencionada explicitamente.

\section{Normatização técnica}

No ano de 2011, as normas da ABNT para produtos de madeira preservada referiam-se apenas aos postes de eletrificação, moirões, dormentes e bobinas para cabos elétricos. Eram elas:

- Norma Brasileira Regulamentadora NBR 6232 - Penetração e retenção de preservativo em postes de madeira (ABNT, 1973). Norma técnica em revisão.

-NBR 6231 - Postes de madeira - Resistência à flexão (ABNT, 1980).

- NBR 8456 - Postes de eucalipto preservado para redes de distribuição de energia elétrica Especificação (ABNT, 1984a). Norma técnica em revisão.

- NBR 8457 - Postes de eucalipto preservado para redes de distribuição de energia elétrica Dimensões - Padronização (ABNT 1984b). Norma técnica em revisão.

- NBR 7190 - Projeto de estruturas de madeira (ABNT, 1997). Norma técnica em revisão.

- NBR 6236 - Madeira para carretéis para

TABELA 2: Consumo brasileiro de madeira em tora na indústria florestal (distribuição percentual por setor e espécie).

TABLE 1: Brazilian wood logs consumption in a forestry industry (percentage distribution by area and species).

\begin{tabular}{lcccc}
\hline \multirow{2}{*}{ Setor } & \multicolumn{4}{c}{ Consumo de madeira em tora $\left(\mathrm{m}^{3}\right)$} \\
\cline { 2 - 5 } & Eucalyptus & Pinus & Total $\left(\mathrm{m}^{3}\right)$ & Total $(\%)$ \\
\hline Celulose e papel & 54.783 .840 & 8.593 .860 & 63.377 .700 & 37,5 \\
Painéis reconstituídos & 4.424 .069 & 8.758 .677 & 13.182 .746 & 25,2 \\
Indústria madeireira & 3.515 .084 & 29.133 .632 & 32.648 .716 & 19,3 \\
Carvão vegetal & 15.401 .191 & - & 15.401 .191 & 9,1 \\
Lenha industrial & 33.156 .894 & 9.399 .442 & 42.556 .336 & 7,8 \\
Outros & 1.674 .144 & 284.695 & 1.958 .839 & 1,2 \\
\hline \multicolumn{1}{c}{ Total } & 112.955 .222 & 56.170 .306 & 169.125 .528 & 100 \\
\hline
\end{tabular}

Fonte: ABRAF (2011). 
fios, cordoalhas e cabos (ABNT 2004).

- NBR 7511 - Dormente de madeira Requisitos e métodos de ensaio (ABNT 2005). Norma técnica em revisão.

- NBR 9480 - Peças roliças preservadas de eucalipto para construções rurais - Requisitos (ABNT, 2009).

Não existe normalização técnica sobre requisitos ou especificações de outros produtos de madeira tratada, bem como procedimentos e metodologias para estudos da durabilidade natural das madeiras nativas ou plantadas, novos produtos preservativos e avaliação laboratorial ou em campo da madeira tratada. Estudos dessa natureza no Brasil são feitos com base nas recomendações da American Wood Protection Association (AWPA), British Standards (BS), American Railway Engineering and Maintenance-of-Way Association (AREMA) e American Society for Testing and Materials (ASTM).

\section{Segundo}

Madtrat

(2008),

0 desenvolvimento de novos produtos de madeira tratada deve ser embasado em especificações técnicas, assegurando, assim, qualidade e satisfação do consumidor final. A proposição de novas normas técnicas e especificações para outros produtos de madeira tratada, assim como a criação de uma marca de conformidade para os produtos de madeira tratada, estariam diretamente ligadas ao crescimento do setor no Brasil.

\section{Principais preservativos utilizados}

Existem diversos produtos que podem ser utilizados para o tratamento preservativo de madeira, conforme lista dos Standards da AWPA (2010). Segundo Brazolin et al. (2007), o IBAMA permite, no Brasil, o uso de arseniato de cobre cromatado (CCA tipo $\mathrm{C}$ ), borato de crobre cromatado (CCB), ciflutrina, cipermetrina, deltametrina, fipronil, IPBC, creosoto, tanino, tribromofenol, quinolinolato de cobre-8, cardendazin, prochloraz, boratos, fluor, além dos preservativos à base de cobre e azole. Segundo Netto (2010), no ano 2010, 90\% das usinas de preservação de madeira no Brasil, sob pressão, utilizavam o CCA, forma óxido, sendo os $10 \%$ restantes com $\mathrm{CCB}$, na forma óxida ou salina.

A efetividade de um tratamento preservativo é avaliada pela retenção e penetração dos preservativos na madeira (ARSENAULT, 1973; REVISTA DA MADEIRA, 2007; MONTANA QUÍMICA, 2008). A retenção é a quantidade de preservativo introduzido e retido na madeira, sendo expressa em massa $(\mathrm{kg})$ de componentes ativos do produto por unidade de volume de madeira tratada; no sistema métrico decimal, a retenção é expressa em $\mathrm{kg}$ / $\mathrm{m}^{3}$ (quilogramas por metro cúbico) e, no sistema inglês, é expressa em lb./pé (libras por pé cúbico), com equivalência de $1 \mathrm{~kg} / \mathrm{m}^{3}$ para $16 \mathrm{lb} / \mathrm{pé}^{3} \mathrm{~A}$ penetração é a profundidade que o preservativo alcança na madeira, sendo comumente avaliada por reações colorimétricas, permitindo a avaliação qualitativa da distribuição do preservativo na região tratável da madeira (SIAU, 1984; MONTANA QUÍMICA, 2008). De acordo com as normas técnicas vigentes da ABNT destinadas à preservação de madeiras, recomenda-se a penetração do produto, em toda a seção do alburno, e retenções variáveis, de acordo com o produto utilizado e o uso final da madeira tratada. Os valores mínimos recomendados de retenção de CCA tipo C, CCB e creosoto, preconizadas pelas normas da ABNT, de acordo com a categoria de uso, podem ser vistos na Tabela 3.

Estudos preliminares recomendam a divisão da categoria 1 (Tabela 3 ) em duas outras, uma correspondendo à situação em que a madeira estaria no interior de construção, fora de contato com o solo, alvenaria ou fundações e protegido de intempéries ou fontes internas de umidade; e outra, em que a madeira estaria no interior de construção, em contato com alvenaria e sem contato com o solo ou fundações, e protegido das intempéries e de fontes internas de umidade. Com isso, a NBR 7190 iria propor seis categorias de uso para a madeira em serviço.

Hartford (1973), Wilkinson (1979), citados por Lepage (1986), e Leightley (2003), citam as seguintes características de um preservativo ideal: ser eficiente na prevenção ou controle do maior número possível de organismos xilófagos; não ser tóxico ao homem, organismos não xilófagos e ao meio ambiente; apresentar penetração profunda e uniforme dentro da madeira; não alterar as propriedades da madeira, como combustibilidade; não ser corrosivo em contato com outros materiais, como metais e plásticos; ser resistente à lixiviação e à volatilidade; apresentar custo acessível e estar disponível no mercado; 
TABELA 3: Valores mínimos de retenção na madeira para os preservativos CCA tipo C, CCB e creosoto recomendados de acordo com sua categoria de uso*.

TABLE 3: Minimal values of wood retentions for the preservatives CCA type C, CCB and creosote, recommended according to the use category system*.

\begin{tabular}{|c|c|c|c|c|c|}
\hline $\begin{array}{c}\text { Categoria } \\
\text { de uso* }\end{array}$ & Condições de Uso & $\begin{array}{c}\text { Retenção } \\
\text { mínima } \\
\text { recomendada } \\
\text { kg i.a. } / \mathrm{m}^{3} \\
\text { (madeira } \\
\text { tratada) }\end{array}$ & $\begin{array}{c}\text { Retenção } \\
\text { mínina de } \\
\text { creosoto } \\
\left(\mathrm{kg} / \mathrm{m}^{3}\right)\end{array}$ & $\begin{array}{l}\text { Ataque de } \\
\text { organismos } \\
\text { xilófagos }\end{array}$ & Aplicação* \\
\hline 1 & $\begin{array}{l}\text { Madeira inteiramente } \\
\text { protegida das intempéries e } \\
\text { não sujeita à reumidificação. } \\
\text { A umidade média de } \\
\text { equilíbrio da madeira varia } \\
\text { entre } 12 \text { e } 18 \%{ }^{* *} \\
\text { Situações: interior de } \\
\text { construções com ou sem } \\
\text { contato com alvenaria, mas } \\
\text { fora do contato com o solo ou } \\
\text { com fundações, e protegido } \\
\text { de intempéries e de fontes } \\
\text { internas de umidade.* }\end{array}$ & 4,0 ou $6,5^{1}$ & - & $\begin{array}{l}\text { Cupim de madeira } \\
\text { seca, cupim- } \\
\text { subterrâneo, } \\
\text { cupim-arborícola, } \\
\text { broca-de-madeira }\end{array}$ & $\begin{array}{c}\text { Carretéis }{ }^{2}, \\
\text { Janelas, móveis } \\
\text { internos, portas, } \\
\text { embalagens, } \\
\text { batentes, } \\
\text { assoalhos, guarda- } \\
\text { corpos, montantes, } \\
\text { subcoberturas de } \\
\text { telhado }\end{array}$ \\
\hline 2 & $\begin{array}{l}\text { Madeira inteiramente } \\
\text { protegida das intempéries, } \\
\text { mas sujeita à reumidificação } \\
\text { ocasional. A umidade média } \\
\text { de equilíbrio da madeira } \\
\text { varia entre } 12 \mathrm{e} 18 \% .^{* *} \\
\text { Situações: interior de } \\
\text { construções, fora de contato } \\
\text { com o solo e continuamente } \\
\text { protegida de intempéries, } \\
\text { que pode ocasionalmente ser } \\
\text { exposta a fontes de umidade.* }\end{array}$ & 4,0 ou $6,5^{1}$ & - & $\begin{array}{l}\text { Cupim de madeira } \\
\text { seca, broca-de- } \\
\text { madeira, cupim- } \\
\text { subterrâneo, } \\
\text { cupim- } \\
\text { arborícola, fungo } \\
\text { embolorador, } \\
\text { manchador e } \\
\text { fungo apodrecedor }\end{array}$ & $\begin{array}{c}\text { Corrimãos, } \\
\text { Lambris, Vigas, } \\
\text { Soleiras, Colunas }\end{array}$ \\
\hline 3 & $\begin{array}{l}\text { Madeira não protegida das } \\
\text { intempéries, ou protegida, } \\
\text { mas sujeita à reumidificação } \\
\text { frequente. A umidade média } \\
\text { de equilíbrio da madeira é } \\
\text { maior ou igual a } 25 \%{ }^{* *} \\
\text { Situações: uso exterior, fora } \\
\text { de contato com o solo e } \\
\text { sujeita a intempéries* }\end{array}$ & 4,0 ou $6,5^{1}$ & - & $\begin{array}{l}\text { Cupim de madeira } \\
\text { seca, broca-de- } \\
\text { madeira, cupim- } \\
\text { subterrâneo, } \\
\text { cupim- } \\
\text { arborícola, fungo } \\
\text { embolorador, } \\
\text { fungo manchador, } \\
\text { fungo apodrecedor }\end{array}$ & $\begin{array}{c}\text { Batentes, Telhas, } \\
\text { Shingles, Tabeira, } \\
\text { Cumeeiras, } \\
\text { Caibros, Terças, } \\
\text { Tesouras, } \\
\text { Móveis externos, } \\
\text { Fechamentos, } \\
\text { Cruzetas para } \\
\text { postes, Carrocerias } \\
\text { de caminhões, } \\
\text { Tampas laterais } \\
\text { e assoalhos para } \\
\text { semirreboques, } \\
\text { Assoalhos para } \\
\text { ônibus e vagões } \\
\text { ferroviários }\end{array}$ \\
\hline
\end{tabular}


TABELA 3: Continuação ...

TABLE 3: Continued ...

\begin{tabular}{|c|c|c|c|c|c|}
\hline $\begin{array}{c}\text { Categoria } \\
\text { de uso* }\end{array}$ & Condições de Uso & 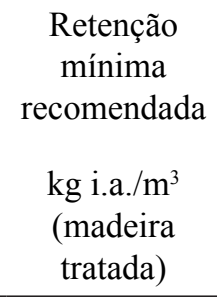 & $\begin{array}{c}\text { Retenção } \\
\text { mínina de } \\
\text { creosoto } \\
\left(\mathrm{kg} / \mathrm{m}^{3}\right)\end{array}$ & $\begin{array}{l}\text { Ataque de } \\
\text { organismos } \\
\text { xilófagos }\end{array}$ & Aplicação* \\
\hline \multirow[b]{2}{*}{4} & \multirow{2}{*}{$\begin{array}{c}\text { Madeira permanentemente } \\
\text { em contato com o solo ou } \\
\text { água doce.** }\end{array}$} & $\begin{array}{c}4,0 \text { ou- } 6,5^{3} \\
9,6^{4} \\
9,6^{5}\end{array}$ & $\begin{array}{l}100^{3} \\
130^{4} \\
130^{4}\end{array}$ & \multirow{2}{*}{$\begin{array}{l}\text { Cupim de madeira } \\
\text { seca, broca-de- } \\
\text { madeira, cupim- } \\
\text { subterrâneo, } \\
\text { cupim- } \\
\text { arborícola, fungo } \\
\text { embolorador, } \\
\text { fungo manchador, } \\
\text { fungo apodrecedor }\end{array}$} & $\begin{array}{c}\text { Peças roliças } \\
\text { (moirões) } \\
\text { Postes } \\
\text { Dormentes }\end{array}$ \\
\hline & & $\begin{array}{c}6,4 \mathrm{a}(9,6 \mathrm{a} \\
12,8)^{6}\end{array}$ & $100-130$ & & $\begin{array}{l}\text { Cercas, Pérgolas, } \\
\text { Playgrounds, } \\
\text { Torres de } \\
\text { resfriamento, } \\
\text { Estacas, Escadas, } \\
\text { Fundações }\end{array}$ \\
\hline 5 & $\begin{array}{l}\text { Madeira permanentemente } \\
\text { em contato com água } \\
\text { salgada.** }\end{array}$ & $24,0-40,0^{7}$ & - & $\begin{array}{l}\text { Perfurador- } \\
\text { marinho, fungo } \\
\text { embolorador, } \\
\text { fungo manchador, } \\
\text { fungo apodrecedor }\end{array}$ & $\begin{array}{c}\text { Colunas, } \\
\text { Defensas, } \\
\text { Pontes, Passarelas }\end{array}$ \\
\hline
\end{tabular}

Em que: * Adaptado de Montana Química S.A. (2008); ** Categoria de uso da madeira, de acordo com a NBR 7190 (ABNT, 1997); ${ }^{1}$ Standards da AWPA (2010), para componentes estruturais de fácil manutenção, reparo ou substituição $\left(4,0 \mathrm{~kg}\right.$ i.a/ $\left./ \mathrm{m}^{3}\right)$ e para componentes estruturais de difícil manutenção, reparo ou substituição, e críticos para o desempenho e segurança do sistema construtivo $\left(6,5 \mathrm{~kg}\right.$ i.a $\left./ \mathrm{m}^{3}\right) ;{ }^{2}$ NBR 6236 (ABNT, 2004); ${ }^{3}$ NBR 9480 (ABNT, 2009), para peças roliças suspensas, fora do contato com o solo $\left(4,0 \mathrm{~kg}\right.$ i.a. $\left./ \mathrm{m}^{3}\right)$ e em contato direto com o solo $\left(6,5 \mathrm{~kg}\right.$ i.a. $\left./ \mathrm{m}^{3}\right) ;{ }^{4}$ NBR 8456 (ABNT, 1984); ${ }^{5}$ NBR 7511 (ABNT, 2005); ${ }^{6}$ Standards da AWPA (2010), para componentes estruturais de fácil manutenção, reparo ou substituição $\left(6,4 \mathrm{~kg} \mathrm{i.a} / \mathrm{m}^{3}\right)$ e para componentes estruturais de difícil manutenção, reparo ou substituição, e críticos para o desempenho e segurança do sistema construtivo $(9,6-$ 12,8 kgi.a. $\left./ \mathrm{m}^{3}\right) ;{ }^{7}$ Standards da AWPA (2010), para ataques menos $\left(24,0 \mathrm{~kg}\right.$ i.a. $\left./ \mathrm{m}^{3}\right)$ e mais severos $\left(40,0 \mathrm{~kg}\right.$ i.a. $\left./ \mathrm{m}^{3}\right)$ de Limnoria sp.

poder ser utilizado em formulações preservativas, ou seja, com mais de um produto preservativo; ser de fácil e segura manipulação, além de ser aceito e normalizado pelas agências reguladoras competentes; permitir acabamentos superficiais após o tratamento preservativo da madeira; permitir o descarte seguro ou a reciclagem da madeira tratada no final da sua vida útil. Segundo Wilkinson (1979), citado por Lepage (1986), e Leightley (2003), dificilmente um preservativo pode apresentar todas essas características, sendo a escolha de um produto sobre aquele que atenda à maioria desses requisitos, levando-se em consideração, também, o local de uso final da madeira tratada. Segundo Leightley (2003), um preservativo que atende à maioria desses requisitos é o CCA, sendo considerado um dos mais eficientes para o tratamento preservativo da madeira, combinando ações de efeito fungicida e inseticida. O CCA tem seu uso restrito em alguns países, devido à presença de arsênio na sua formulação, que é um elemento nocivo à saúde humana. No Brasil, até o ano de 2011, nenhuma restrição quanto ao uso de CCA havia sido adotada.

\section{Principais métodos de tratamento}

Os principais métodos de tratamento preservativo da madeira no Brasil são aqueles realizados sob pressão, em autoclave, utilizando o método Bethell. Segundo Hunt e 
TABELA 4: Ingredientes ativos e métodos de tratamento sem pressão, recomendados para madeiras expostas em áreas externas.

TABLE 4: Active ingredients and non- pressure treatment process recommended for outdoor exposed wood.

\begin{tabular}{|c|c|c|c|c|c|}
\hline $\begin{array}{c}\text { Categoria } \\
\text { de uso }^{1}\end{array}$ & Condições de Uso & Produtos $^{3}$ & $\begin{array}{l}\text { Retenção } \\
\text { mínina }^{3}\end{array}$ & Penetração na madeira ${ }^{3}$ & Aplicação $^{3}$ \\
\hline 1 & $\begin{array}{l}\text { Madeira inteiramente protegida } \\
\text { das intempéries e não sujeita à } \\
\text { reumidificação. A umidade média } \\
\text { de equilíbrio da madeira varia entre } \\
12 \text { e } 18 \%{ }^{1} \\
\text { Situações: interior de construções } \\
\text { com ou sem contato em alvenaria, } \\
\text { mas fora do contato com o solo } \\
\text { ou com fundações, e protegido de } \\
\text { intempéries e de fontes internas de }^{\text {umidade. }}{ }^{2}\end{array}$ & $\begin{array}{l}\text { Cipermetrina, } \\
\text { deltametrina, } \\
\text { fipronil, } \\
\text { ciflutrina, } \\
\text { IPBC }\end{array}$ & $\begin{array}{l}\text { Não } \\
\text { disponível: } \\
\text { (consulta ao } \\
\text { fabricante) }\end{array}$ & Superficial & $\begin{array}{l}\text { Imersão, } \\
\text { pincelamento, } \\
\text { aspersão. }\end{array}$ \\
\hline & $\begin{array}{l}\text { Madeira inteiramente protegida } \\
\text { das intempéries, mas sujeita } \\
\text { à reumidificação ocasional. A } \\
\text { umidade média de equilíbrio da } \\
\text { madeira varia entre } 12 \text { e } 18 \% .{ }^{1}\end{array}$ & \multirow{4}{*}{$\begin{array}{l}\text { Cipermetrina, } \\
\text { deltametrina, } \\
\text { fipronil, } \\
\text { ciflutrina, } \\
\text { IPBC }\end{array}$} & \multirow{4}{*}{$\begin{array}{l}\text { Não } \\
\text { disponível: } \\
\text { (consulta ao } \\
\text { fabricante) }\end{array}$} & \multirow{4}{*}{ Superficial } & \multirow{4}{*}{$\begin{array}{l}\text { Duplo-vácuo, } \\
\text { imersão, } \\
\text { pincelamento, } \\
\text { aspersão }\end{array}$} \\
\hline 2 & $\begin{array}{l}\text { Situações: interior de } \\
\text { construções, fora de contato } \\
\text { com o solo e continuamente } \\
\text { protegida de intempéries, que pode } \\
\text { ocasionalmente ser exposta a fontes } \\
\text { de umidade. }\end{array}$ & & & & \\
\hline \multirow[t]{2}{*}{3} & $\begin{array}{l}\text { Madeira não protegida das } \\
\text { intempéries, ou protegida, mas } \\
\text { sujeita à reumidificação frequente. } \\
\text { A umidade média de equilíbrio da } \\
\text { madeira é maior ou igual a } 25 \% .{ }^{1}\end{array}$ & & & & \\
\hline & $\begin{array}{l}\text { Situações: uso exterior, fora de } \\
\text { contato com o solo e sujeita a } \\
\text { intempéries }^{2}\end{array}$ & & & & \\
\hline
\end{tabular}

Em que: ${ }^{1}$ Categoria de uso da madeira, de acordo com a NBR 7190 (ABNT, 1997); ${ }^{2}$ Adaptado de Montana Química S.A. (2008); ${ }^{3}$ Fonte: Brazolin et al. (2007).

Garratt (1962), esse método foi desenvolvido e patenteado por John Bethell, em 1838, na Inglaterra, e consiste nas etapas de vácuo inicial, seguida da admissão do preservativo, sem a entrada de ar no cilindro da autoclave, indo para uma fase de pressão de impregnação do produto na madeira. Passado esse tempo, há o esvaziamento do preservativo no cilindro da autoclave e aplicação de um vácuo final (etapa esta não citada na patente inicial). $\mathrm{O}$ método Bethell utilizava, originalmente, preservativos oleosos, mas atualmente os preservativos hidrossolúveis também são utilizados. Tal método é amplamente utilizado no Brasil para tratamento das madeiras dos gêneros Eucalyptus e Pinus. Nesse processo, podem ser utilizados o CCA, CCB e o creosoto.

Segundo Silva (2006), o método de substituição de seiva é muito utilizado no Brasil, principalmente nas pequenas e médias propriedades rurais, sendo considerado eficiente e de baixo custo, recomendado, exclusivamente, para moirões ou peças de menor diâmetro. Outros métodos caseiros ou sem pressão externa também são utilizados, apesar de não serem os mais ambientalmente seguros, principalmente nos ambientes de 
menor agressividade, conforme categorias 1, 2 e 3, listadas no Anexo D da NBR 7190 (ABNT, 1997). Segundo Brazolin et al. (2007), diversos produtos e métodos sem pressão podem ser utilizados para a madeira nessas condições, conforme pode ser visto na Tabela 4.

Segundo Brazolin et al. (2007), para os painéis reconstituídos podem ser adicionados à cola inseticidas como ciflutrina, cipermetrina, deltametrina e fipronil, para usos nas classes $1,2 \mathrm{e}$ 3. Estas classes descritas representam uma situação de exposição menos agressiva, ou seja, onde as madeiras serão aplicadas fora de contato com o sole e podem ser facilmente substituídas em caso de necessidade.

\section{TENDÊNCIAS DOSETOR DE PRESERVAÇÃO DE MADEIRAS NO BRASIL}

O Brasil apresenta potencialidades de alcançar novos mercados, com novos produtos de madeira tratada, e ampliar o comércio dos produtos tradicionais, principalmente com o emprego das madeiras dos gêneros Eucalyptus e Pinus. Segundo Revista Referência (2009), a expansão da atividade rural contribui substancialmente para o aumento da demanda de madeira tratada. Um mercado promissor é o do setor elétrico, consolidando a utilização de postes e, mais recentemente, o mercado de cruzetas de eucalipto tratado. Borges (2008), ao avaliar a potencialidade do uso de cruzetas tratadas de Eucalyptus, verificou que as madeiras de Corymbia citriodora e Corymbia cloeziana se mostraram como potenciais na produção desses produtos, sendo o seu custo menor em relação à cruzeta de concreto armado ou aço. Segundo Netto (2010), o setor de construção civil é também de grande potencial para a madeira tratada, sendo impulsionado pelas facilidades de construção, transporte, rapidez e versatilidade, gerando economia, conforto e beleza.

$\mathrm{O}$ setor de preservação de madeiras tem se mantido em sintonia com outros países onde a atividade já é consolidada. Por isso, o setor é emergente e se mostra atento aos novos produtos preservativos e processos de tratamento. Preservativos tradicionais, outrora utilizados em larga escala, como o lindane, pentaclorofenol e outros clorados, já foram descartados e retirados do comércio. É crescente a preocupação mundial com as questões ambientais e ergonômicas, envolvendo todos os segmentos da cadeia produtiva: produtores, processadores $\mathrm{e}$ consumidores da madeira tratada. A maior participação dos consumidores e disponibilização de informações gera o desenvolvimento de novos produtos, mais seguros e de baixa toxicidade para os homens e de menor impacto ao meio ambiente, em substituição àqueles de reconhecido efeito preservativo da madeira, mas portador de efeitos deletérios à saúde humana e ao meio ambiente. De forma geral, as pesquisas objetivam a busca de produtos de máxima eficácia e que atendam esses requisitos.

Com relação aos produtos existentes no mercado, a United States Environmental Protection Agency (EPA), órgão responsável pelo gerenciamento ambiental de produtos nos Estados Unidos, concluiu que a madeira tratada com CCA não apresenta perigo para a saúde das pessoas. $\mathrm{O}$ elemento arsênico entra na composição do CCA na forma óxida, ou seja, na sua forma mais estável e, por isso, não sofre fácil liberação da madeira uma vez reagido. Este é um elemento de reconhecido efeito carcinogênico para o ser humano, mas os seus efeitos são mitigados na madeira tratada, quando participa da formulação do CCA, em associação como cobre e cromo ou ainda pela utilização de acabamentos superficiais, tais como stains ou vernizes. Como medida preventiva, o EPA restringiu o uso de madeira tratada com CCA destinada para usos residenciais, a partir de 31 de dezembro de 2003. Nos Estados Unidos, o seu uso passou a ser restrito para usos não residenciais e sem contato contínuo com as pessoas (LEIGHTLEY, 2003, LEBOW, 2010). Mesmo com essas medidas restritivas, o volume de madeira tratada com CCA ainda continuou relativamente alto. Segundo Jambeck et al. (2007), estima-se que no ano de 2008, 9,7 milhões de metros cúbicos de madeira foram tratadas com CCA, estendendo assim o volume de madeiras tratadas ainda em serviço, com durabilidade estimada entre 10 e 40 anos. Segundo o CSIRO (2008), outros países também apresentam restrições totais ou parciais ao uso de CCA, destacando-se o Japão, Indonésia, Suécia, Alemanha e Austrália. As restrições se devem também às mesmas preocupações destacadas pela EPA, pela presença do arsênio, grau de lixiviação e descarte da madeira tratada. 
Além das preocupações sobre os riscos de produtos à base de arsênio e cromo na saúde humana, existem também preocupações sobre os impactos desses produtos no meio ambiente. Segundo Lebow et al. (2004), o grau de lixiviação desses preservativos no meio ambiente depende de vários fatores. O nível de retenção do preservativo, bem como a espécie e idade da madeira, teor de umidade, processo de tratamento, intemperismo e condição de exposição, são situações que influenciam a eficácia do tratamento químico e a durabilidade da madeira tratada. Estudos demonstrando a quantificação dos químicos lixiviados em escala de campo, sob condições naturais de uso, ainda são poucos, demandando de um maior aprofundamento. Aqui reside a necessidade fundamental de se respeitar o período de fixação após a madeira ser tratada em autoclave, a fim de que a saúde e a segurança da população e do meio ambiente sejam preservadas.

Nos Estados Unidos, os preservativos alternativos ao CCA, para uso residencial englobam formulações embasadas em ingredientes ativos, como azoles, quaternários de amônio e cobre. O cobre é o ingrediente ativo inorgânico, com atividade fungicida e ação limitada contra cupins. Os azoles e quaternários de amônio são eficientes fungicidas, capazes de inibir a ação dos fungos tolerantes ao cobre (AWPA, 2007). Os preservativos à base de cobre, azoles e quaternários de amônio possuem variações nas suas formulações, não contêm cromo e arsênio e podem ser alternativos em situações em que o CCA apresentar restrições. Esses preservativos contêm elevada concentração de cobre, o que pode potencializar os riscos aos organismos aquáticos (HANSAN et al., 2008). No Brasil, a segunda versão da NBR 9480 (ABNT, 2009) já preconizava o uso de preservativo à base de cobre e azole para o tratamento preservativo de moirões de eucalipto para uso em contato com o solo ou fora dele.

Os azoles e os quartenários de amônio foram citados como potenciais substitutos do CCA no $39^{\circ}$ Fórum Internacional sobre Preservação da Madeira, realizado em Istambul, Turquia, no ano de 2008. $\mathrm{O}$ evento internacional é considerado referência no setor de preservação de madeiras, apresentando as principais tendências e os mais importantes resultados de pesquisas em todo o mundo. Esses preservativos, entretanto, quando comparados ao
CCA, apresentam alguns problemas, como elevado custo, menor poder de fixação e consequente maior lixiviação, além de maior susceptibilidade a fungos emboloradores, exigindo-se a aplicação de aditivos para controlar esse tipo de fungo (REVISTA DA MADEIRA, 2008).

Métodos alternativos visando ao aumento da resistência da madeira a organismos xilófagos também são pesquisados. Segundo Hill (2009), nos países nórdicos europeus, muitos estudos estão sendo conduzidos em direção à modificação física e química da madeira. No exemplo de modificação física, a termorretificação ou o tratamento térmico da madeira tem sido mais frequentemente fruto de pesquisas; na modificação química, as pesquisas são realizadas a partir da acetilação ou da furfurilação, não existindo estudos sobre a toxicidade $\mathrm{e}$ confiabilidade destes produtos e processos. Pessoa et al. (2006) avaliaram a termorretificação da madeira de Eucalyptus grandis, submetida ao ataque do cupim de madeira seca, Cryptotermes brevis, observaram que, para as condições do experimento, o tratamento térmico não foi suficientemente eficaz para conceder à madeira total resistência contra a ação dos xilófagos, sugerindo novos estudos nessa área.

\section{CONCLUSÕES}

Com base na revisão apresentada nesse trabalho, pode-se concluir que o setor de preservação de madeiras no Brasil apresenta os seguintes aspectos:

- O setor possui uma quantidade reduzida de produtos de madeira tratada, resumindo-se a poucos segmentos industriais;

- Embora crescente, o consumo de madeira tratada é, ainda, insignificante quando comparado ao de outros países;

- A despeito das vantagens da madeira tratada, outras matérias-primas mais restritivas, dos pontos de vista ambiental e econômico, estão sendo mais utilizadas;

- Setores emergentes da economia nacional, como construção civil, embalagens, transmissão elétrica estão se somando aos setores tradicionais de consumo de madeira tratada, como componentes de ferrovias e usos rurais;

- O CCA é o produto preservativo mais utilizado e, no Brasil, não existem restrições ao seu uso;

- No Brasil não existem evidências sobre o 
uso de produtos alternativos ao $\mathrm{CCA}$ e ao $\mathrm{CCB}$, em escala comercial, para o tratamento industrial da madeira, a curto prazo.

\section{AGRADECIMENTOS}

Os autores agradecem a Fundação de Amparo à Pesquisa do Estado de Minas (FAPEMIG), pelo apoio financeiro aos projetos de preservação de madeiras no Estado de Minas Gerais, e a Montana Química S.A., pelo suporte técnico aos estudos científicos de preservação de madeiras no Brasil.

\section{REFERÊNCIAS BIBLIOGRÁFICAS}

ABRAF. Anuário estatístico da ABRAF 2011: ano base 2010. Brasília, 2011. $130 \mathrm{p}$.

ALVES, G. K. A.; SINAY, M. C. F. Os dormentes ferroviários, seu tratamento e o meio ambiente. In: RIO DE TRANSPORTES, 3., 2005, Rio de Janeiro. Anais... Rio de Janeiro, 2005. CD ROM.

AMERICAN WOOD PROTECTION
ASSOCIATION. 2007 AWPA book of standards. Birmingham, Alabama, AWPA, 2007. $491 \mathrm{p}$.

ASSOCIAÇÃO BRASILEIRA DE NORMAS TÉCNICAS. NBR 6231: Postes de madeira: resistência à flexão. Rio de Janeiro: ABNT, 1980. $4 \mathrm{p}$.

ASSOCIAÇÃO BRASILEIRA DE NORMAS TÉCNICAS. Penetração e retenção de preservativo em postes de madeira: NBR 6232. Rio de Janeiro: ABNT, 1973. 19 p.

ASSOCIAÇÃO BRASILEIRA DE NORMAS TÉCNICAS. Postes de eucalipto preservado para redes de distribuição de energia elétrica: especificação: NBR 8456. Rio de Janeiro: ABNT, 1984a. 31 p.

ASSOCIAÇÃO BRASILEIRA DE NORMAS TÉCNICAS. - Postes de eucalipto preservado para redes de distribuição de energia elétrica: dimensões - padronização: NBR 8457. Rio de Janeiro: ABNT, 1984b. 5p.

ASSOCIAÇÃO BRASILEIRA DE NORMAS TÉCNICAS. Projeto de estruturas de madeira: NBR 7190. Rio de janeiro: ABNT, 1997. $107 \mathrm{p}$.

ASSOCIAÇÃO BRASILEIRA DE NORMAS TÉCNICAS. Madeira para carretéis para fios, cordoalhas e cabos: NBR 6236. Rio de Janeiro: ABNT, 2004. 5 p.
ASSOCIAÇÃO BRASILEIRA DE NORMAS TÉCNICAS. Dormente de madeira: requisitos e métodos de ensaio: NBR 7511. Rio de Janeiro: ABNT, 2005. $18 \mathrm{p}$.

ASSOCIAÇÃO BRASILEIRA DE NORMAS TÉCNICAS. Peças roliças preservadas de eucalipto para construções rurais: requisitos: ABNT 9480. 2. ed. Rio de Janeiro: ABNT, 2009. $12 \mathrm{p}$.

BRAZOLIN, S. et al. Preservação de madeiras - sistema de classe de risco - revisão da NBR 7190 - Anexo D. In: ENCONTRO NACIONAL ABPM, 7, São Paulo, SP, 2007. Anais... 2007. Disponível em <(http://www.abpm.com.br/ pdf/IPT-Sergio_Brazolin.pdf)>. Acesso: 06 de junho de 2011.

BORGES, C. C. Potencialidade do uso de cruzetas de madeira tratada. 2008. 105 p. Dissertação (Mestrado em Engenharia Florestal) - Universidade Federal de Paraná, Curitiba, 2008

BROTERO, F. A. Estudo sobre um preservativo de madeira. Boletim do Instituto de Engenharia, São Paulo, SP, 1933. p. 24-29.

CALIL JÚNIOR, C.; DIAS, A. A. Utilização da madeira em construções rurais. Revista da madeira, Curitiba,PR,n. 88,mar.,2005.Disponívelem: $<$ (http:// www.remade.com.br/br/revistadamadeira materia. num $=714 \&$ subject $=$ ConsConstr\&title $=$ Utilização da madeira em construções rurais) $>$. Acesso 24 de maio de 2011.

CAVALCANTE, M. S. Histórico da preservação de madeiras. In: LEPAGE, E. S. Manual de Preservação de Madeiras. São Paulo: IPT, 1986. p. 9-39.

COMMONWEALTH SCIENTIFIC AND INDUSTRIAL RESEARCH ORGANISATION - CSIRO. The facts about CCA-treated timber. 2008. Disponível em <(http://www.csiro.au/ resources/CCATreatedTimber.html)>. Acesso: 19 de maio de 2011.

FRANCISCHINELLI, A. Postes de eucalipto tratado. Revista da madeira, Curitiba, PR, n. 97, jun., 2006. Disponível em: $<$ (http://www.remade.com.br/br/revistada madeira_materia.php?num $=918 \&$ subject $=E$ mais\&title $=$ Postes de eucalipto tratado) $>$. Acesso em: 22 de maio de 2011.

GERALDO, F. C. A madeira de eucalipto para postes. Revista da madeira, Curitiba, PR, n. 59, set., 2001. Disponível em: $<$ (http:// www.remade.com.br/br/revistadamadeira materia.php? num $=23 \&$ subject $=$ Postes $\&$ title $=$ 
A $\% 20$ Madeira $\% 20 \mathrm{de} \% 20$ Eucalipto $\% 20$ para\%20Postes)>. Acesso em: 22 de maio de 2011.

GERALDO, F. C. Madeira preservada é boa alternativa para a construção. Revista da madeira, Curitiba, PR, n. 82, jul., 2004. Disponível em $<$ (http://www.remade.com.br/br/revistadamadeira materia.um $=572 \&$ subject $=$ Preservação $\&$ title $=$ Ma de ir a \% 20 preservad a \% 20 é \% 20 boa $\% 20$ alternativa $\% 20$ para $\% 20$ a $\% 20$ construção)>. Acesso em: 24 de maio de 2011.

GERALDO, F. C. Mourões para cercas: a renovação necessária. Revista da madeira, Curitiba, PR, n. 115, jul., 2008. Disponível em: <(http://www. remade.com.br/br/revistadamadeira_materia. php?num $=1292 \&$ subject $=\mathrm{E}$ mais\&title=Mourões para cercas: a renovação necessária) $>$. Acesso em: 23 de maio de 2011.

HARTFORD, W. H. Chemical and physical properties of wood preservatives and woodpreservative systems. In: NICHOLAS, D.D. Wood deterioration and its prevention by preservative treatments. Syracuse: Syracuse University Press. 1973. $2^{\circ}$ vol, cap. 2, p. 1-120.

HASAN, A. R.; HU, L.; SOLO-GABRIELE, H.; CAI, Y.; FIEBE, L.A. Leachability of arsenic, chromium and copper from weathered treated wood. In: ANNUAL MEETING OF IRG - WP (INTERNATIONAL RESEARCH GROUP ON WOOD PROTECTION), 39., 2008, Istanbul, Turkey. Proceedings... 2008. IRG/WP 08-50255

HILL, C. A. S. The Potential for the Use of Modified Wood Products in the Built Environment. In.: INTERNATIONAL CONFERENCE ON NON-CONVENTIONAL MATERIALS AND TECHNOLOGIES, 11., 2009, Bath, United Kingston. Proceedings... Bath, United Kingston, 2009.

HUNT, G. M.; GARRATT, G. A. Preservación de la madera. Barcelona: Salvat Ed., 1962. $486 \mathrm{p}$.

JAMBECK, J. et al. CCA-Treated wood disposed in landfills and life-cycle trade-offs with waste-to-energy and MSW landfill disposal. 2007.

LEBOW, S.; COOPER, P.; LEBOW, P. Variability in evaluating environmental impacts of treated wood. Madison, USA: U.S. Department of Agriculture, Forest Service, Forest Products Laboratory. 2004. 10 p. Disponível em : >(http:// www.fpl.fs.fed.us/documnts/fplrp/fpl_rp620.pdf)>. Acesso em 08 de junho de 2011.

LEBOW, S. T. Wood preservation. In: FOREST PRODUCTS LABORATORY. Wood Handbook: wood as an engineering material. Madison, USA: Department of Agriculture, Forest Service, Forest Products Laboratory. 2010. p. 15-1 - 1528. Disponível em: <(http://www.fpl.fs.fed.us/ documnts/fplgtr/fplgtr190/chapter_15.pdf) > . Acesso em 07 de julho de 2011.

LEIGHTLEY, L. E. Protection of wood using combinations of biocides. In: GOODELL, B.; NICHOLAS, D. D.; SCHULTZ, T. P. Wood deterioration and preservation: advances in our changing world. Washington, USA. 2003. p. 390-398. (ACS Symposium Series 845).

LEPAGE, E. S. Preservativos e sistemas preservativos. In: Manual de Preservação de Madeiras. São Paulo: IPT, 1986. p. 279-342.

MADTRAT - MADEIRAS TRATADAS. Disponível em: $\quad<$ http://www.madtrat.com.br/preservacao. php>. Acesso em: 06 de junho de 2011.

MONTANA QUÍMICA S.A. Madeira Tratada com Osmose ${ }^{\circledR}$ K33 C - Óxido: Informativo Técnico - Divisão Osmose. São Paulo, SP: Montana Química S.A. 2008. Disponível em <(http:// www.montana.com.br/Perguntas-Freq/MadeiraTratada/CCA-Osmose-K33-C)>. Acesso: 24 de maio de 2011.

PESSOA, A. M. C. et al. Avaliação da madeira termorretificada de Eucalyptus grandis, submetida ao ataque de cupim de madeira seca, Cryptotermes brevis. Scientia Forestalis, Piracicaba, SP, n. 72, p. 11-16, dez., 2006.

REVISTA DA MADEIRA. Tecnologia amplia possibilidades de usos. Revista da madeira, Curitiba, PR, n. 109, dez., 2007. Disponível em: <(http:// www.remade.com.br/br/revistadamadeira_materia. $\mathrm{um}=1187 \&$ subject $=$ Preservantes $\&$ title $=$ Tecnologia amplia possibilidades de usos $<\mathrm{b}></ \mathrm{b}>$. Acesso em: 22 de maio de 2011.

REVISTA DA MADEIRA. Madeira: tendências internacionais na preservação de madeiras. Revista da madeira. 2008. Disponível em: $<$ (http://www.remade.com.br/br/noticia. php?num $=5058 \&$ title $=$ Tendências $\% 20$ internacionais $\% 20$ na $\% 20$ preservação $\% 20$ de\%20madeiras)>. Acesso: 06 de junho de 2011.

REVISTA REFERÊNCIA. A indústria da madeira 
preservada sob pressão no Brasil. Revista (Boletim de extensão).

Referência, n. 88, 2009.

STEINER, C. Utilização prática da madeira SIAU, J. F. Transport processes in wood. Berlim; de eucalipto roliça, selecionada tratada em Heidelberg; New York: Spring-verlag, 1984. 245 p. autoclave na construção civil. . In: ENCONTRO SILVA, J. C. Métodos práticos de tratamento BRASILEIRO EM MADEIRAS E ESTRUTURA de madeira na propriedade rural. Viçosa: UFV, DE MADEIRA. 7., 2000, São Carlos. Anais... São PEC, Núcleo de difusão de tecnologia, 2006. 40 p. Carlos: EBRAMEM, 2000. CD ROM. 